\title{
Netflix e a narrativa transmídia como meio de aproximação cultural
}

\author{
Nara Luiza de Paula Socci ${ }^{\mathrm{i}}$
}

\begin{abstract}
RESUMO
A partir de vídeos selecionados do canal do Youtube da Netflix Brasil, este artigo examina a maneira como a narrativa transmídia desenvolve-se, elencando o caminho que a constelação de produtos midiáticos percorreu entre a mídia-fonte - as séries da Netflix: Stranger Things (2016), La Casa de Papel (2017) e The Gambit Queen (2020) - até chegar aos vídeos promocionais no Youtube. Sob a luz de Jenkins (2009), é possível entender como a cultura de convergência é importante para esse processo. A isso, Figueiredo $(2016 ; 2017)$ complementa com as características da narrativa transmídia e sua intersecção no campo da intermidialidade. A hipótese aqui defendida é a de que, ao utilizar a narrativa transmídia a partir de elementos da cultura brasileira, é possível uma aproximação maior entre a mídia-fonte e seu público-alvo.
\end{abstract}

Palavras-chave: Netflix; Narrativa transmídia; Netflix Brasil.

\begin{abstract}
Based on selected videos from Netflix Brazil's Youtube channel, this article examines how transmedia storytelling develops, analyzing the path that the constellation of media products took from the source media - the Netflix series Stranger Things (2016), La Casa de Papel (2017), and The Gambit Queen (2020) - until the promotional videos on Youtube. According to Jenkins (2009), it is possible to understand how the convergence culture is important for this process. Figueiredo $(2016 ; 2017)$ complements it with the characteristics of transmedia storytelling and its intersection in the field of intermediality. The hypothesis defended here is that by using transmedia storytelling and elements of Brazilian culture, it is possible to bring the source media to the target audience closer together.
\end{abstract}

Keywords: Netflix; Transmedia storytelling; Netflix Brazil.

\section{INTRODUÇÃO}

\footnotetext{
${ }^{\mathrm{i}}$ Mestranda no Programa de Pós-Graduação em Letras pela Universidade Federal de São Paulo (UNIFESP). ORCID: https://orcid.org/0000-0002-8042-0288 | nasocci@gmail.com
} 
Vivemos conectados. Estamos conectados pela internet e por nossos dispositivos - smartphones, tablets, notebooks etc. A qualquer momento, podemos ter acesso a infinitas informações sobre os mais variados assuntos com uma rapidez jamais vista na história. Cada período da humanidade contribuiu para a evolução dos processos interacionais, tendo em vista que "são inseparáveis das formas de socialização e cultura que são capazes de criar, de modo que o advento de cada novo meio de comunicação traz consigo um ciclo cultural" (SANTAELLA, 2003, p. 25). Consideramos que, além da interação das mídias em nossas vidas, estamos vivendo uma cultura de convergência. (cf. JENKINS, 2009).

Em 2016, Henry Jenkins concedeu uma entrevista para o periódico Intercom: Revista Brasileira de Ciências da Comunicação, em que aponta que:

\begin{abstract}
Convergência e conexão são o que impulsiona [sic] a mídia agora e aquilo que assegura que a mídia seja importante em todos os níveis, desde o mais micro e hiperlocal, até o mais macro. Se a nossa sociedade é mediada, é POR CAUSA da convergência e da conexão, porque todos os aspectos das nossas vidas são tocados pela mídia e porque mais e mais de nós temos a capacidade de comunicar nossas ideias por meio de múltiplos canais de mídia. (JENKINS, KALINKE \& ROCHA, 2016, p. 176)
\end{abstract}

Como aponta Jenkins, a conexão e a convergência mostram-se essenciais em nossas relações com as mídias. Destacamos esses dois aspectos, mas o estudioso (2009, p. 29) elenca a necessidade da comunicação, de uma inteligência coletiva e de uma cultura participativa para que a cultura de convergência seja efetiva, já que é necessário "fluxo de conteúdos através de múltiplas plataformas de mídia". O consumidor irá participar dessa cultura e existirá uma fluidez entre os consumidores ao migrar entre as mídias.

Tal migração de público passou a ser aproveitada pela Netflix que, além de sua própria plataforma, possui perfis verificados em outras mídias, como Youtube, Instagram, Facebook, Twitter e Spotify, nas quais a participação de seus seguidores pode ser vista por meio do engajamento de suas postagens. Por isso, tem-se visto a criação de cada vez mais conteúdos voltados para os fãs, como é o caso do objeto de estudo do presente artigo, a Netflix Brasil.

A Netflix Brasil possui forte presença nas redes sociais, contando com milhões de seguidores em seus perfis nas plataformas do Youtube, Instagram, Facebook, Twitter e 
Spotify, e gerando constantemente conteúdo para seus assinantes, que, por meio "de pedaços e fragmentos de informações extraídos do fluxo midiático e transformados em recursos atrás dos quais [compreendem a] vida cotidiana", constroem suas próprias "mitologia[s] pessoa[is]" (JENKINS, 2009, p. 30). Assim, o fluxo midiático torna-se um processo social ligado à ideia de inteligência coletiva, pois "faz novas exigências de seus consumidores e depende da participação ativa de comunidade de conhecimento" (JENKINS, 2009, p. 49).

O objetivo deste artigo é destacar como a intermidialidade e a narrativa transmídia podem ser utilizadas para compreender a relação de aproximação entre o produto e o público específico - neste caso, o consumidor da Netflix Brasil. Os exemplos selecionados são retirados da conta oficial da Netflix Brasil no Youtube. Este trabalho dispensa atenção à Netflix Brasil, que possui como foco os assinantes brasileiros, sendo possível encontrar vídeos em que atores estrangeiros experimentam comidas típicas brasileiras ou tentam pronunciar palavras do português brasileiro; desse modo, a Netflix Brasil apresenta diversas formas criativas em sua busca de maior aproximação com o público brasileiro.

\section{NETFLIX E PRODUTOS MIDIÁTICOS}

Contando com mais de 200 milhões de assinantes ${ }^{1}$ e ganhadora dos principais prêmios do audiovisual - Emmy, Golden Globes e Oscar -, a Netflix consagrou-se como produtora e distribuidora de filmes e séries no mercado mundial. Seu catálogo é composto por produções de diversos países, sendo possível ao telespectador assistir as produções no idioma original ou com dublagens e/ou legendas em seu próprio idioma. Por ser um serviço de streaming ${ }^{2}$ e on demand ${ }^{3}$, a Netflix produz conteúdo adicional em diversas plataformas com o objetivo de ampliar a integração com seus assinantes.

O Brasil é o terceiro maior mercado da empresa e o segundo em número de assinantes $^{4}$, contando com cerca de 17 milhões de pessoas que assinam o serviço ${ }^{5}$. A narrativa seriada já é uma forma conhecida do público brasileiro desde os anos 1980 (cf. BALOGH \& NASCIMENTO, 2011), o que provavelmente influencia a receptividade deste público à plataforma da Netflix. Em Lopes e Mungioli (2015), é possível verificar que, desde 2014, há um aumento na produção da narrativa seriada. A Netflix iniciou a 
produção de séries no Brasil em 2016 e atualmente possui mais de dez produções brasileiras. Tal fenômeno indica que a empresa segue duas tendências: a de produção de conteúdo nacional para o público brasileiro e a de produção de mídias seriadas que estão em alta para o mesmo público.

A plataforma vai além, utilizando personalidades conhecidas pela massa brasileira em narrativas que interligam seu conteúdo com tais artistas. O telespectador que não conhece a premissa de uma série ou a personalidade escolhida - além de outros elementos da cultura brasileira -, terá a chance de entender o conteúdo reduzido. Por isso, a plataforma cria vários produtos que, associados às séries, auxiliam e incrementam a recepção do telespectador.

Essa iniciativa da Netflix Brasil produz uma constelação de produtos midiáticos que pode ser estudada à luz das pesquisas sobre intermidialidade. Sendo um termo relativamente novo e que pode abranger diferentes áreas de conhecimentos, a intermidialidade possui diferentes definições e abordagens. Neste trabalho, faremos uso da perspectiva de Clüver (2012, p. 9), que "implica todos os tipos de interrelação e interação entre mídias", discutindo posteriormente como se dá tal constelação de produtos midiáticos criados pela Netflix Brasil.

Segundo a professora Camila Figueiredo, as relações entre intermidialidade e transmidialidade podem ser entendidas a partir da ideia de Irina Rajewsky em palestra na Faculdade de Letras da UFMG. Figueiredo (2017, p. 77) ressalta a importância de "reconhecer a relevância que a transmídia adquiriu nos últimos tempos e o importante papel que os estudos de mídia têm desempenhado no sentido de compreender as especificidades dos mais diversos produtos culturais contemporâneos". A essa perspectiva, soma-se a ideia de que a transmídia - segundo a perspectiva de Jenkins seria uma forma de transmidialidade, mas, para Rajewsky, a substituição de um termo por outro é equivocada: um seria planejado e o outro seria constituído de maneira pontual. Portanto, a narrativa transmídia pode ser concebida para um ou mais dos processos abaixo:

Na prática, portanto, a narrativa transmídia é uma estratégia normalmente utilizada para (a) fazer uma ponte entre um texto principal - geralmente o filme - e suas sequências; (b) prenunciar evoluções no enredo de uma obra; (c) expandir a narrativa ou completar suas lacunas; (d) desenvolver histórias de personagens secundários, outros detalhes e perspectivas da narrativa; (e) oferecer um apoio para o ingresso de um novo público à franquia; (f) construir 
universos que não podem ser esgotados em uma só mídia. (FIGUEIREDO, 2016, p. 47-48)

Aparentemente, a Netflix Brasil tem como objetivo principal "oferecer um apoio para o ingresso de um novo público à franquia" ao utilizar-se da narrativa transmídia em seus vídeos no Youtube. Tais vídeos são curtos, variando entre 3 e 15 minutos, nos quais uma narrativa é construída e protagonizada por uma personalidade brasileira conhecida. Neste sentido, aspectos culturais brasileiros são utilizados para que uma aproximação também seja desenvolvida, buscando como resultado o público brasileiro atraído para assistir à série ou ao filme.

Os produtos criados não são essenciais para o entendimento da narrativa principal, mas a narrativa principal é indispensável para o entendimento desses produtos midiáticos. Para compreendermos como a narrativa transmídia da Netflix Brasil funciona, é necessário ter em mente que grande parte de seus assinantes são consumidores que interagem e participam em suas redes sociais. Esse telespectador ativo é um reflexo da cultura de convergência, que seria o "fluxo de conteúdos através de múltiplas plataformas de mídia, à cooperação entre múltiplos mercados midiáticos e ao comportamento migratório dos públicos dos meios de comunicação" (JENKINS, 2006, p. 29,).

Em decorrência da cultura de convergência, a narrativa transmídia passou a ser uma ferramenta utilizada pelos conglomerados de mídias. Para que a experiência de seus consumidores seja plena, é necessário que eles procurem tais conteúdos em outros canais. A Netflix faz uso da convergência e incentiva seus assinantes a consumirem esse conteúdo, propiciando-lhes o trânsito por plataformas como Youtube, Instagram, Facebook, Twitter e Spotify, visto que "cada produto determinado é um ponto de acesso à franquia como um todo" (JENKINS, 2006, p. 138).

A narrativa transmídia (transmedial storytelling) pode ser construída a partir de duas variações: a primeira inicia-se de um texto-base que, ao atingir certa popularidade, obterá continuações e/ou derivações. Já a segunda variação levando-se em conta a utilização de um texto-base em diversas plataformas, ou seja, uma única plataforma não abrange todo storyworld (o "mundo da narrativa") planejado: para compreender toda a narrativa, o público precisará acessar diferentes mídias (cf. RYAN, 2013). Jenkins (2009, p. 138) aponta ainda que "uma história transmídia desenrola-se através de múltiplas 
plataformas de mídia, com cada novo texto contribuindo de maneira distinta e valiosa para o todo. Na forma ideal de narrativa transmídia, cada meio faz o que faz de melhor". Stranger Things e Xuxa

Em 15 de julho de 2016, estreava na Netflix a série Strangers Things. Ambientada nos anos 1983 na cidade americana de Hopkins, a trama apresenta o sumiço de Will Byers e sua jornada mundo invertido (Upside down), enquanto, no mundo real, sua mãe, Joyce Byers, e seus amigos tentam encontrá-lo. A série foi premiada no Emmy e no Golden Globes, tornando-se um sucesso de crítica e público. Até a escrita do presente artigo, Stranger Things conta com três temporadas, tendo sido reproduzida por cerca de 64 milhões de pessoas $^{6}$ e alcançado a posição de quinta produção mais vista da plataforma a quarta temporada encontra-se na fase de produção.

Para essa série, a Netflix Brasil escolheu a apresentadora Xuxa, conhecida pelo público brasileiro desde os anos 1980, para recriar um quadro de seu programa que envolvia ler cartas de fãs. Temos na Figura 1 uma imagem real da apresentadora em seu programa e outra em que Xuxa aparece no produto criado pela Netflix, intitulado Stranger Things - Xuxa e o baixinho que sumiu (2016) ${ }^{7}$.

Figura 1: Xuxa em seu programa nos anos $1980^{8}$ e na propaganda da Netflix ${ }^{9}$ (2016)

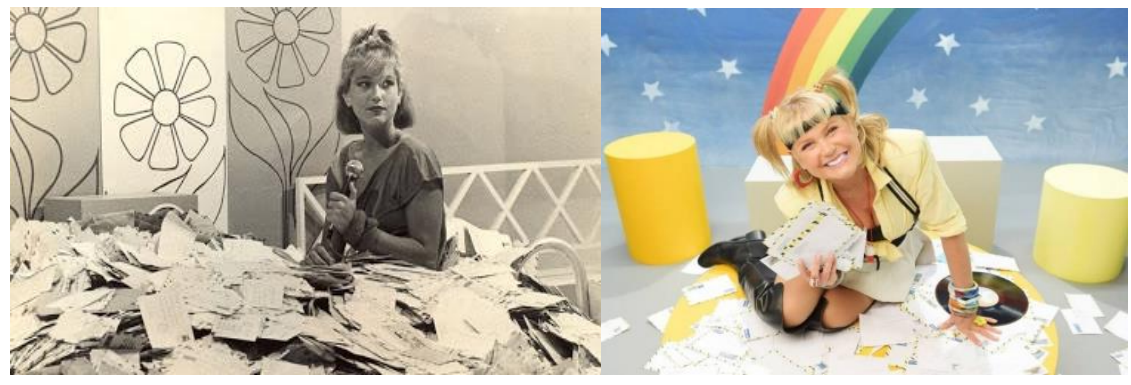

Nos primeiros segundos do vídeo, temos Eleven - uma das protagonistas de Strangers Things - entrando na sala de estar e ligando a televisão. A personagem começa a assistir ao programa de Xuxa pela televisão $(0: 15)^{10}$ : a apresentadora está lendo uma carta de Joyce Byers (0:26), que narra o desaparecimento do filho (0:49). Ao final, cenas da série são mostradas (2:03).

Desde o título do produto - em especial, através do termo "baixinho", utilizado em referência a Will - já é possível relacionar a apresentadora com a antonomásia pela qual é conhecida nacionalmente ("Rainha dos baixinhos"), devido aos anos que trabalhou 
como apresentadora de programas infantis. A Netflix Brasil utiliza-se de um bordão conhecido pelos brasileiros, "Senta aí, Cláudia!" (0:20), protagonizado por Xuxa no programa "Clube da Criança" de 1984, tornando-se um meme. O vídeo mostra a dificuldade da leitura em palavras da língua inglesa, como "Hopkins" (0:32), e confirma que o tempo em que acontece a narrativa é nos anos de 1980, visto que a própria apresentadora afirma que sua filha Sasha ainda não teria nascido (0:38). Sendo assim, contamos com três momentos que representam a década de 1980: Xuxa, que é apresentadora (realidade); o tempo em que acontece a série (ficção), e o tempo em que ocorre esse produto de mídia (ficção).

A respeito de produções cinematográficas dos anos 1980, Figueiredo (2018) cita Kathleen Loock, em seu artigo "Retro-remaking: The 1980s Film Cycle in Contemporary Hollywood Cinema" (2016):

\begin{abstract}
muitas produções que remetem a essa década tendem a celebrar os originais, e sua estética dos anos 1980 evoca ligações sentimentais com seus filmes e séries de televisão, bem como às memórias de infância associadas a eles. Além disso, ao retomar conteúdos bem-sucedidos em épocas anteriores, as produções culturais atuais se aproveitam do valor comercial e cultural que tais produções conquistaram ao longo de décadas, o que se revela uma estratégia bastante lucrativa, já que poderão ser consumidas tanto pela geração original quanto por uma nova. (FIGUEIREDO, 2018, p. 3)
\end{abstract}

Segundo Figueiredo (2018), a escolha da década de 1980 é uma tendência da Netflix - tanto na série quanto pela Netflix Brasil, que se utiliza de referências brasileiras do referido período. A série ambientada nos 1980 anos traz características dos Estados Unidos dessa época, embora possamos apontar elementos que podem ser reconhecidos pelos brasileiros, tais como músicas (The Clash e David Bowie compõem a trilha sonora da série), jogos de RPG (Dungeons \& Dragons), filmes (Star Wars: O império contraataca e E.T., o extraterrestre, ambos de 1982). Embora compartilhem componentes culturais, o país no qual se passa a série continua a ter uma cultura diferente, portanto, distante da realidade do telespectador brasileiro. Entretanto, ao utilizar-se da imagem de Xuxa, uma aproximação e uma identificação são criadas pelo conteúdo do vídeo do Youtube que levará o telespectador à mídia-fonte, a série Stranger Things.

Destaca-se que a série possui elementos sobrenaturais - telefones que tocam sem explicação e luzes que piscam sozinhas - que, ao longo da série, são explicados. A apresentadora Xuxa já teve seu nome associado a histórias sobrenaturais, tal como o caso 
de sua boneca amaldiçoada (1:49) ou o de seu disco que, ouvido de trás para frente (1:57), mostrava uma música de mal pressagio ${ }^{11}$. Ambos os elementos aparecem no vídeo, com Xuxa afirmando que dará uma boneca para quem ajudar a encontrar Will e no enunciado por ela proferido: “Quem quer ouvir o meu disquinho ao contrário?”. Em seguida, a apresentadora emite um som sem nexo, parodiando as histórias contadas a seu respeito. A narrativa transmídia inicia-se de uma narrativa principal - a série Stranger Things - e uma história secundária acerca desse mundo ficcional é desenvolvida. Essa nova narrativa pode tornar-se uma forma de acesso para a mídia principal (cf. JENKINS, 2009): elementos da série são expostos e a personalidade brasileira, conhecida popularmente, é utilizada para que seja acessível e que alcance o público brasileiro.

Para que a narrativa transmídia efetivamente aconteça, é necessário a participação dos consumidores. Assim, a Netflix Brasil utiliza-se de easter eggs ${ }^{12}$ que podem ser reconhecidos facilmente ou por meio da inteligência coletiva, conceito de Pierre Lévy (2003); o conhecimento surge a partir do compartilhamento de informações de um grupo (JENKNINS, 2009, p. 57). A Netflix Brasil cria intersecções entre a série e elementos culturais brasileiros, esperando que seu consumidor identifique cada componente que compõe essa constelação de produtos.

\section{LA CASA DE PAPEL E WHINDERSON NUNES}

La Casa de Papel é uma produção espanhola que entrou no catálogo da Netflix em 2017. Sua quarta temporada ocupa o terceiro lugar de produção mais assistida - 65 milhões de telespectadores nas quatro primeiras semanas após o lançamento -, além de ter ganhado o Emmy Internacional. A série acompanha um assalto na Casa da Moeda da Espanha.

Whindersson Nunes também quer La Casa de Papel pra ontem (2020) ${ }^{13}$ foi o vídeo criado pela Netflix Brasil para a divulgação da nova temporada da série. Protagonizado pelo comediante brasileiro,

\footnotetext{
Windersson [sic] Nunes, o youtuber mais consumido do Brasil, carrega também o status de influenciador digital, afinal, administra um dos canais mais bem sucedidos do YouTube no mundo (mais de 26 milhões de inscritos e mais de 2 bilhões de visualizações de seus vídeos). [...] Então, Whindersson, por ter um público consumidor superior a 20 milhões não atenderia a um público
} 
específico, logo, a sua influência pode ser pulverizada devida a diversidade de públicos existentes em torno de sua rede. (PINHEIRO \& POSTINGUEL, 2018, p. 115)

Whindersson Nunes torna-se um produto midiático pelo fato de atrair consumidores a consumirem seus vídeos. Ciente do engajamento que o comediante pode alcançar, a Netflix Brasil utiliza-se de sua imagem para construir uma nova narrativa dentro do universo de La Casa de Papel. Com alguns personagens do elenco original da série e o youtuber brasileiro, a Netflix Brasil recria uma cena comum de La Casa de Papel: os personagens reunidos para escutar o Professor, o qual podemos ver nos primeiros segundos do vídeo promocional. Neste caso, o comediante autodomina-se como Piauí (0:21) - estado em que Whindersson nasceu -, visto que na série os personagens usam codinomes de países ou cidades. Além disso, ele veste-se como um dos assaltantes da série: macacão vermelho e a máscara com o rosto do pintor Salvador Dalí. Whindersson Nunes apresenta seu "plano infalível” (0:36), o que podemos associar ao personagem Cebolinha, da Turma da Mônica, como podemos ver na Figura 2.

Figura 2: Cena de Whindersson Nunes apresentando o plano infalível ${ }^{14}$ (2020).

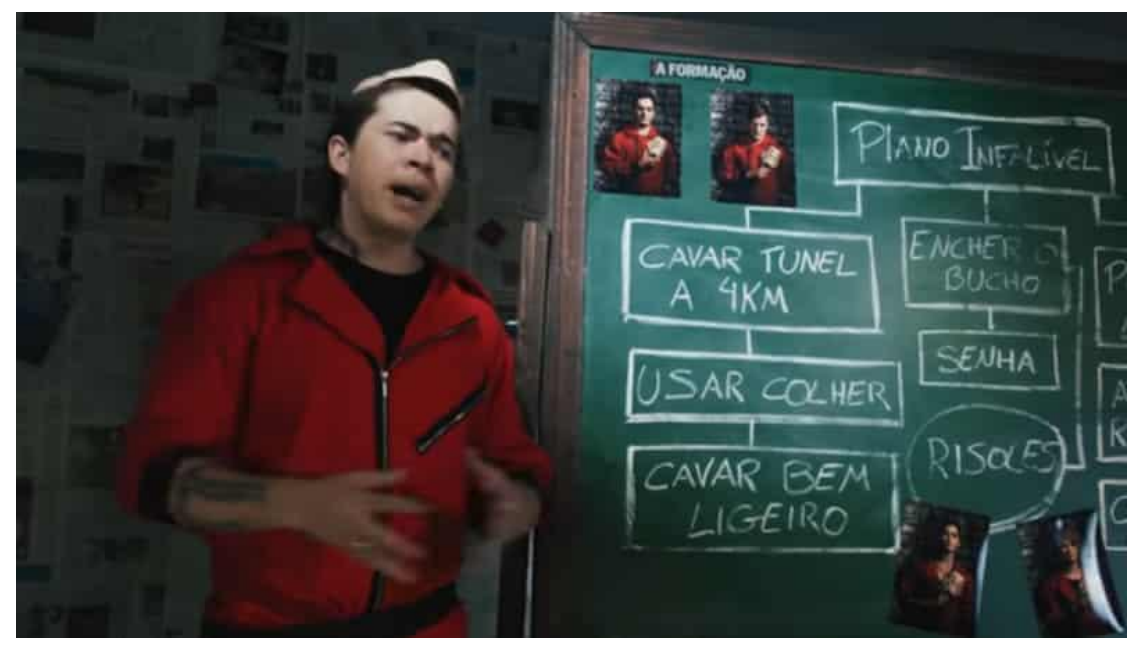

Uma das atrizes da série interrompe o comediante (0:44) para explicar que é uma atriz, não a personagem da série (0:47). Nesse momento, Whindersson Nunes contraargumenta, dizendo que ambos trabalham na mesma empresa (0:55), fazendo uma propaganda de seu próprio especial de comédia (0:58), disponível na plataforma da Netflix. Assim, o comediante começa a pedir spoilers da nova temporada (1:03) e a 
questionar o futuro da série para cada um dos atores presentes (1:07). Com sucessivas respostas negativas, o comediante frustra-se e utiliza um meme popular brasileiro, o "papel de trouxa" (1:24), criando um trocadilho com o título da série. Entende-se que ele fica chateado ao não receber os spoilers que deseja (1:27); portanto, os atores mostramno uma cena inédita (1:41), que apenas seria vista dali a quatro dias (1:55), quando do retorno da série iria retornar.

Figura 3: Whinderson Nunes e os atores de La Casa de Papel ${ }^{15}$ (2017)

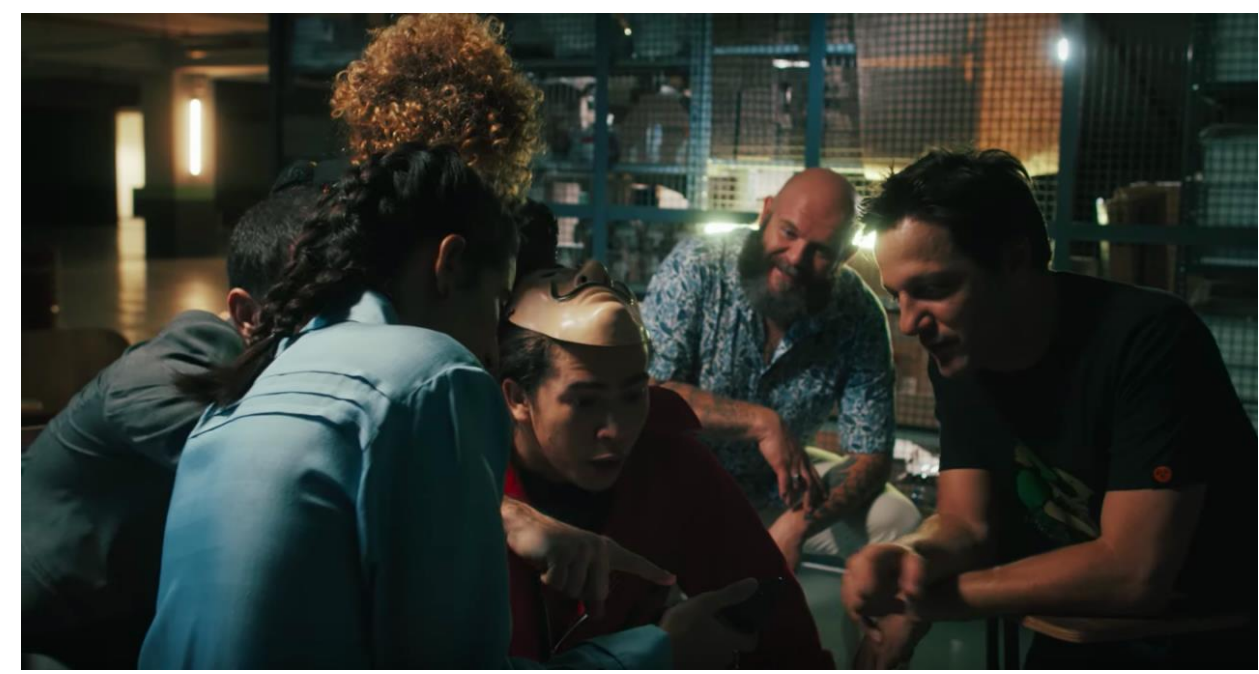

A nova narrativa transmídia criada pela Netflix Brasil representa "um novo texto contribuindo de maneira distinta e valiosa para o todo" (JENKINS, 2009, p. 138): uma nova história é construída dentro do universo da série e aproxima esse mundo ficcional do Brasil, novamente tornando-se um novo ponto de acesso e instigando o seu consumidor a assistir à nova temporada.

Vale ressaltar que Whindersson Nunes possui números expressivos na plataforma do Youtube. É possível supor que esse fato tenha sido importante na escolha do comediante para a criação do vídeo, pois a Netflix é "uma indústria onde uma única empresa pode ter raízes em vários diferentes setores de mídia" (JENKINS, 2009, p. 138). Como o foco do presente artigo é o Youtube, podemos concluir que a Netflix Brasil deseja atrair diferentes consumidores por todos os meios possíveis para que comecem a assistir à mídia-fonte - a série La Casa de Papel. Assim, ao se utilizar de um dos maiores 
youtubers brasileiros, a empresa atrai um público diverso que poderá fidelizar-se como um assinante de sua plataforma.

\section{THE QUEEN'S GAMBIT E MANU GAVASSI}

The Queen's Gambit - em português, O Gambito da Rainha - é uma minissérie da Netflix que estreou em 2020. Ela concentra-se na vida de Beth Harpor, uma menina órfã e prodígio no xadrez, que possui uma dependência em medicamentos. A série tornouse a sexta produção mais assistida, alcançando 62 milhões de telespectadores, e ganhou o Golden Globes de 2021. Lançado em fevereiro de 2021, o vídeo Manu Gavassi em O Cliente Tem Sempre Razão: O Gambito da Rainha ${ }^{16}$ mostra a atriz e cantora Manu Gavassi, que também é influenciadora digital. É importante ressaltar esse status, pois

\footnotetext{
Para Abidin (2008), os influenciadores representam uma boa síntese do que são, hoje, as celebridades digitais: nativos da internet que ganham a vida por estarem na internet. Nesse mesmo sentido, ainda que não tratando dos influenciadores digitais, França (2014, p. 29) afirma que "[...] as novas tecnologias, o barateamento e facilitação dos processos de produção, a abertura dos canais de circulação e divulgação de produtos possibilitam quase a qualquer um se lançar na rede [...]" e, como resultado, alcançar um status de celebridade por meio dessa visibilidade facilitada. (KARHAWI, 2020, p. 5)
}

Como influenciadora digital, Manu Gavassi possui uma presença ativa nas redes sociais, o que é um chamariz para novos consumidores para a Netflix Brasil. Sua participação no BBB 20 seria mais um atrativo para a empresa, pois a cantora e atriz também atrairia o público que consome o conteúdo das mídias antigas - programas de televisão em canais abertos -, que "irão interagir de formas cada vez mais complexas" (JENKINS, 2009, p. 33). Assim, o público migra da televisão, acompanha-a nas redes sociais e, consequentemente, consumirá os produtos midiáticos criados pela Netflix Brasil.

A história contada pela Netflix inicia-se com Manu Gavassi lendo reclamações de clientes, focando na sugestão da mudança na narrativa de The Queen's Gambit (0:15) de que Larissa Manoela - atriz também contratada da Netflix - atue nessa versão (0:58). Com a negativa, Gavassi assume a reinterpretação (1:12). A cantora interpreta a sugestão do cliente (1:17) e ironiza a sugestão, afirmando que toda dramaticidade da série deixaria 
de existir se a protagonista não tivesse seus conflitos internos (2:20), mas afirma que o cliente sempre tem razão $(2: 31)$.

Figura 4: Cena da minissérie The Queen's Gambit ${ }^{17}$ (2020) e Manu Gavassi reinterpretando a protagonista de The Queen's Gambit ${ }^{18}$ (2021)

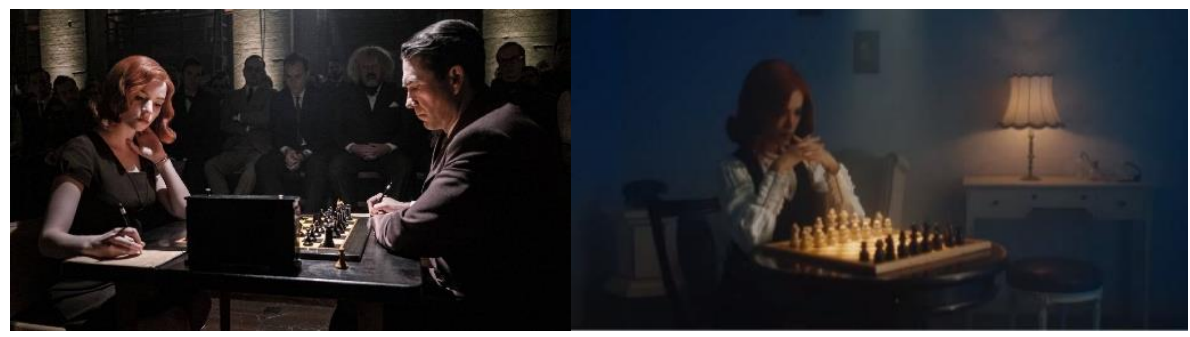

A fluidez de Manu Gavassi em transitar em diferentes nichos é um dos trunfos utilizados pela Netflix para alcançar a ideia de que "uma boa narrativa transmídia trabalha para atrair múltiplas clientelas, alterando um pouco o tom do conteúdo de acordo com a mídia" (JENKINS, 2009, p. 138). O universo paralelo criado na mídia no Youtube - no qual temos Manu Gavassi como protagonista e uma mudança significativa na trama da série - mostra como "cada obra oferece[r] experiências novas" (p. 139), já que no vídeo temos uma nova visão da história no mesmo universo ficcional.

\section{CONSIDERAÇÕES FINAIS}

Vivemos em uma sociedade cada vez mais fragmentada e multicultural, e a Netflix conseguiu unir em uma única plataforma produções de diversas nacionalidades para um público diverso. Mas como fazemos parte de uma cultura de convergência, uma única plataforma não é o suficiente para consumidores cada vez mais conectados.

Observando a constelação de produtos midiáticos criados pela Netflix Brasil, percebemos que é uma tendência utilizar-se da narrativa midiática, tendo como objetivo criar novas formas para o ingresso na mídia-fonte. Ademais, aspectos culturais brasileiros são inseridos para que o conteúdo estrangeiro ganhe características nacionais. Entrelaçados às narrativas seriadas, tais aspectos são eficazes apenas para o destinatário brasileiro, que reconhecerá as personalidades escolhidas - Xuxa, Whindersson Nunes e 
Manu Gavassi. Nesse sentido, é possível identificar os demais elementos culturais contidos nas narrativas no Youtube que podem ser a chave de acesso para a mídia-fonte. Verificamos a efetividade da narrativa transmídia, pois temos a migração de telespectadores entre as mídias, consumidores juntando aspectos da série e das histórias contadas por meio de informações compartilhadas (JENKINS, 2009). Interconexões improváveis são criadas e geram um conteúdo que enriquece o mundo ficcional das séries.

\section{Referências}

BALOGH, Anna Maria.; NASCIMENTO, Geraldo Carlos do. As astúcias da linguagem na narrativa seriada. In: LOPES, Maria Immacolata Vassalo de (Org.). Ficção televisiva transmidiática no Brasil: plataformas, convergência, comunidades virtuais. Porto Alegre: Sulina, 2011. $\quad$ p. $151 \quad$ - $197 . \quad$ Disponível em: https://ia600105.us.archive.org/11/items/FiccoTelevisivaTransmiditicaNoBrasil/Ficc\% C3\%A7\%C3\%A3o\%20televisiva\%20transmidi\%C3\%A1tica\%20no\%20Brasil.pdf. Acesso em: 19 abr. 2021.

BRASIL, Netflix. Stranger Things: Xuxa e o baixinho que sumiu. Youtube, 04/08/2016. Disponível em: https://www.youtube.com/watch?v=2t-AIbErqts. Acesso em: 19 abr. 2021.

Whindersson Nunes também quer La Casa de Papel pra ontem. Youtube, 30/03/2020. Disponível em: https://www.youtube.com/watch?v=MKs2-qTOc70. Acesso em: 19 abr. 2021.

Manu Gavassi em O Cliente Tem Sempre Razão: O Gambito da Rainha. Youtube, 15/02/2021. Disponível em: https://www.youtube.com/watch?v=jpHYRL4yNb8. Acesso em: 19 abr. 2021.

CLÜVER, Claus. Intermidialidade. In: PÓS: Revista do Programa de Pós-graduação em Artes da EBA/UFMG. [S.I.], p. 8-23, 2012. Disponível em: https://periodicos.ufmg.br/index.php/revistapos/article/view/15413. Acesso em: 12 mai. 2021.

FIGUEIREDO, Camila Augusta Pires de. Narrativa Transmídia: modos de narrar e tipos de histórias. In: Letras, v. 26, n. 53, 2016. p. 45-64.

Expandindo os limites: a transmídia no campo da intermidialidade. In: Aletria: Revista de Estudos de Literatura, v. 27, n. 2, 2017. p. 69-82.

A nostalgia dos anos 1980 nas produções da Netflix. In: III Jornada Internacional GEMInIS. 2018. Disponível em: https://bit.ly/2KbR9aL. Acesso em: 11 mai. 2021.

JENKINS, Henry. Cultura da Convergência. 2 ed. São Paulo: Aleph, 2009. 
; KALINKE, Priscila; ROCHA, Anderson. Convergência e conexão são o que impulsiona a mídia agora. In: INTERCOM - RBCC, v. 39, n. 1, 2016. p. 213-219.

KARHAWI, I. Notas teóricas sobre influenciadores digitais e Big Brother Brasil. In: ECompós, [S.I.], 2020. p. 1-22.

LA CASA DE PAPEL. Criador: Álex Pina. Diretor(es): Jesús Colmenar, Koldo Serra, Álex Rodrigo e Javier Quintas. Produtor(es): Álex Pina et al. Elenco: Úrsula Corberó et al. Espanha: Netflix. (Séries: $4^{\mathrm{a}}$ Temporada: 03 de abril de 2020. 8. cap.), 4K (Ultra HD).

LÉVY, P. A inteligência coletiva: por uma antropologia do ciberespaço. $4^{\mathrm{a}}$. ed. São Paulo: Loyola, 2003.

LOPES, Maria Immacolata Vassalo de.; MUNGIOLI, Maria Cristina Palma. Brasil: tempo de séries brasileiras? In: Anuário Obitel 2015: Relações de gênero na ficção televisiva. Porto Alegre, 2015.

PINHEIRO, Wesley Moreira; POSTINGUEL, Danilo. O desempenho de Whindersson Nunes na promoção de campanhas publicitárias e no engajamento pelo YouTube. In: Mediação, v. 20, n. 26, 2018. p. 113-125.

SANTAELLA, Lúcia. Da cultura das mídias à cibercultura: o advento do pós-humano. In: Famecos, v. 10, n. 22, 2003. p. 23-32.

RYAN, Marie-Laura. Narrativa transmídia e transficcionalidade. In: Celeuma, v. 2, n. 3, 2013.

STRANGER THINGS. Criador(es): Matt Duffer, Ross Duffer. Diretor(es): Matt Duffer, Ross Duffer. Produtor: Shawn Levy. Elenco: Millie Bobby Brown et al. Estados Unidos: Netflix.

THE QUEEN'S GAMBIT. Criador(es): Scott Frank, Allan Scott. Diretor: Scott Frank. Produtor(es): Marcus Loges, Mick Aniceto. Elenco: Anya Taylor-Joy et al. Estados Unidos: Netflix.

Recebido em: 24/05/2021

Aceito em: 24/08/2021

\footnotetext{
1 Netflix ultrapassa marca de 200 milhões de assinantes, Folha de São Paulo, 19/01/2021 https://www1.folha.uol.com.br/mercado/2021/01/netflix-ultrapassa-marca-de-200-milhoes-deassinantes.shtml. Acesso em: 18 de mai. de 2021.

2 Tecnologia que a reprodução do conteúdo é feita por meio da internet, não sendo necessário fazer o download do arquivo.

${ }^{3}$ Material que pode ser consumido em qualquer tempo e dispositivo que o assinante desejar.
} 
4 Dados retirados do site: https://canaltech.com.br/resultados-financeiros/netflix-brasil-e-3o-maiormercado-e-2o-em-numero-de-assinantes-166515/. Acesso em: 05 de mai. de 2021.

${ }^{5}$ Dados retirados do site: https://tecnoblog.net/363097/netflix-chega-a-17-milhoes-de-assinantes-e-superatv-paga-no-brasil/. Acesso em: 05 de mai. de 2021.

${ }^{6}$ Dados retirados do site: https://www.gq.com.au/entertainment/film-tv/these-are-the-mostwatched-netflixoriginal-series-in-history/image-gallery/9fae3de0f3d854e059b92311d02ad7c0?pos=7. Acesso em: $20 \mathrm{de}$ mai. de 2021.

${ }^{7}$ Disponível em: https://www.youtube.com/watch?v=2t-AIbErqts. Acesso em: 20 de mai. de 2021.

${ }^{8}$ Imagem disponível em: http://xou-xuxa.blogspot.com/2013/. Acesso em: 17 de ago. de 2021.

9 Imagem disponível em: https://cultura.estadao.com.br/noticias/televisao,era-uma-vez-uma-rainha-quegostava-de-rir-de-si-mesma,10000070793. Acesso em: 17 de ago. de 2021.

${ }^{10}$ Por conta da lei de direitos autorais, os vídeos mencionados no presente artigo foram descritos e cada ação foi indicada no tempo que ela acontece no vídeo disponível no Youtube.

11 Dados retirados do site: https://aventurasnahistoria.uol.com.br/noticias/reportagem/xuxa-e-suasmusicas-ao-contrario-lenda-urbana-mais-famosa-do-brasil.phtml. Acesso em: 17 de mai. de 2021.

12 Em tradução para o português: "ovos de Páscoas". Easter eggs são as referências, "surpresas", que o telespectador encontra em alguma mídia audiovisual que pode ser facilmente reconhecida ou pode-se demorar para encontrá-la. Essas referências, normalmente, podem ser a outros filmes/séries ou elementos da cultura pop. O termo, de origem americana, faz alusão com a caça aos ovos na Páscoa americana.

${ }^{13}$ Disponível em: https://www.youtube.com/watch?v=MKs2-qTOc70. Acesso em: 20 de mai. de 2021.

14 Imagem disponível em: https://plataoplomo.com.br/whindersson-nunes-em-la-casa-de-papel-vementender-essa-historia/. Acesso em: 17 de ago. de 2021.

15 Imagem disponível em: https://hugogloss.uol.com.br/tv/series/la-casa-de-papel-4-whindersson-nunesfica-chocado-com-spoiler-de-elenco-em-video-maravilhoso-assista/. Acesso em: 17 de ago. de 2021.

16 Disponível em: https://www.youtube.com/watch?v=jpHYRL4yNb8\&t=2s. Acesso em: 20 de mai. de 2021.

17 Imagem disponível em: https://revistagalileu.globo.com/Cultura/noticia/2020/11/os-enxadristas-queinspiraram-os-personagens-de-o-gambito-da-rainha.html. Acesso em: 17 de ago. de 2021.

18 Imagem disponível em: https://exitoina.uol.com.br/noticias/tv-e-series/manu-gavassi-estrela-novaversao-entediante-de-o-gambito-da-rainha-assista.phtml. Acesso em: 17 de ago. de 2021. 